\title{
Comparison of the Serum Tumor Markers S100 and Melanoma-inhibitory Activity (MIA) in the Monitoring of Patients with Metastatic Melanoma Receiving Vaccination Immunotherapy with Dendritic Cells
}

\author{
UGUR USLU $^{1 *}$, STEFAN SCHLIEP $^{1 *}$, KLAUS SCHLIEP $^{2 *}$, MICHAEL ERDMANN $^{1}$, \\ HANS-UWE KOCH ${ }^{1}$, HANS PARSCH ${ }^{3}$, STINA ROSENHEINRICH ${ }^{1}$, DORIS ANZENGRUBER ${ }^{1}$, \\ ANJA KATRIN BOSSERHOFF ${ }^{4}$, GEROLD SCHULER ${ }^{1}$ and BEATRICE SCHULER-THURNER ${ }^{1}$ \\ ${ }^{1}$ Department of Dermatology, and ${ }^{3}$ Central Laboratory, Universitätsklinikum Erlangen, \\ and ${ }^{4}$ Institute of Biochemistry (Emil Fischer Center), \\ Friedrich-Alexander-University Erlangen-Nürnberg (FAU), Erlangen, Germany; \\ ${ }^{2}$ Department of Biology, University of Massachusetts Boston, Boston, MA, U.S.A.
}

\begin{abstract}
Background: In patients with melanoma, early dissemination via lymphatic and hematogenous routes is frequently seen. Thus, besides clinical follow-up examination and imaging, reliable melanoma-specific serological tumor markers are needed. Patients and Methods: We retrospectively compared two serum markers for melanoma, S100 and melanoma-inhibitory activity (MIA), for monitoring of patients with metastatic melanoma under either adjuvant or therapeutic vaccination immunotherapy with dendritic cells $(D C)$. Serum was obtained from a total of 100 patients (28 patients in stage III and 72 patients in stage IV, according to the American Joint Committee on Cancer 2002) at regular intervals during therapy, accompanied by follow-up imaging. Results: When relapse was detected, both markers often remained within normal range. In contrast, in patients with metastatic measurable disease receiving therapeutic and not adjuvant DC vaccination, an increase of both markers was a strong indicator for disease progression. When comparing both markers in the whole study population, MIA showed a superior sensitivity to detect disease progression. Conclusion: S100 and MIA are highly sensitive
\end{abstract}

This article is freely accessible online.

*These Authors share first authorship.

Correspondence to: Dr. med. Ugur Uslu, MD, Friedrich-AlexanderUniversity Erlangen-Nürnberg (FAU), Department of Dermatology, Universitätsklinikum Erlangen, Ulmenweg 18, D-91054 Erlangen, Germany. Tel: +49 091318535000, e-mail: ugur.uslu@ukerlangen.de

Key Words: Cancer, cancer care, prognostic marker, biomarker, melanoma therapy, BRAF inhibition, checkpoint inhibition. tumor markers for monitoring of patients with melanoma with current metastases, but less sensitive for monitoring of tumorfree patients. In the current study, MIA had a slightly superior sensitivity to detect progressive disease compared to S100 and seems to be more useful in monitoring of patients with metastatic melanoma receiving immunotherapy.

With its ability to disseminate early via lymphatic and hematogenous routes, melanoma represents one of the most aggressive solid tumors. Melanoma with a tumor thickness of more than $1 \mathrm{~mm}$ is already considered as 'high risk', and the prognostic value of positive sentinel lymph node status has been approved for this group of patients (1-3). In patients with unresectable distant metastases, kinase inhibitors and immune checkpoint-blockade antibodies have prolonged overall survival in clinical trials and have been approved for metastatic melanoma (4-9). Vaccination immunotherapy with dendritic cells (DCs) in patients with metastatic melanoma showed promising results in clinical trials (10-13).

Two tumor markers are usually used for the monitoring of patients with melanoma, the proteins S100 and melanomainhibitory activity (MIA). S100 represents a family of calcium-binding proteins differentially expressed in a large variety of tissues (14). They are found in the cytosol as well as extracellularly, but a mechanism of secretion has not been identified to date (14). Lacking enzymatic activity, S100 mainly exerts its calcium-dependent signaling functions via effector proteins (15). In patients with melanoma, S100 is most likely secreted during cell damage (16) and is widely used in immunohistochemistry (17). Hauschild et al. showed that serum S100 indeed correlates with the clinical course in patients with advanced-stage melanoma (18). Moreover, the German melanoma guidelines recommend serum S100 
measurement in patients with melanoma (19), highlighting its reliability in melanoma follow-up.

MIA represents a highly restricted protein actively secreted by melanoma cells (20). A crucial role of MIA for tumor cell detachment from the cell matrix in the process of metastatic dissemination is assumed (20). Like S100, the serum MIA level represents a highly specific tumor marker in melanoma (21).

However, the superiority of one of these two serum tumor markers over the other in monitoring of melanoma is discussed controversially (21-25). Thus, in this study, S100 and MIA were compared for monitoring of patients with metastatic melanoma receiving vaccination immunotherapy with DCs. Additionally, the sensitivity of both serum tumor markers to detect either recurrent disease in an adjuvant setting or reduction/increase of tumor burden in patients with measurable metastatic disease was analyzed.

\section{Patients and Methods}

We retrospectively analyzed S100 and MIA in a cohort of 100 patients with melanoma who received vaccination immunotherapy with DCs between 2002 and 2009 (Table I). The patients had disease either stage III or stage IV, as classified by the American Joint Committee on Cancer 2002 (26) (Table I). DC immunotherapy was performed within clinical trials (90 patients) $(10,27)$ or as compassionate use (10 patients). Clinical trials were approved by the appropriate Medical Ethical Review Board and regulatory authorities and patients signed written informed consent forms after detailed oral and written explanation of the nature, significance, and consequence of the treatment. Treatment was either started in an adjuvant setting in tumor-free patients or in a therapeutic setting in patients with measurable and unresectable metastases. Every three months, follow-up imaging with magnetic resonance imaging of the brain and computed tomographic scan of the neck, chest, and abdomen in addition to full-body skin examinations and measurement of the serum tumor markers S100 and MIA was performed. At each subsequent staging examination (a total of 688 events), disease was classified either as stable, progressive, or in remission. Progressive disease was defined as increasing size or number of metastases; a decline in these parameters was defined as disease remission. Only staging results with a clear trend for the tumor burden were included in the analysis. In disease-free patients, every new metastasis detected clinically or with the above-mentioned imaging examinations was considered as progressive disease.

Laboratory analysis. From 2002 until April 2004, S100 was measured using the LIA-mat ${ }^{\circledR}$ Sangtec ${ }^{\circledR} 100$ assay, a two-step incubation assay with two catcher and one tracer antibodies, as indicated by the manufacturer (AB Sangtec Medical, Bromma, Sweden). The upper normal limit was $0.15 \mu \mathrm{g} / \mathrm{l}$. Starting from April 2004, S100 levels were determined using the Elecsys ${ }^{\circledR}$ S100 assay according to the manufacturer's instructions (Roche Diagnostics, Mannheim, Germany). The upper normal limit for S100 was $0.09 \mu \mathrm{g} / \mathrm{l}$ until June 2006 and 0.10 $\mu \mathrm{g} / \mathrm{l}$ after June 2006. MIA levels were measured with a one-step enzyme-linked immuno-sorbent assay (ELISA) kit according to the manufacturer's instructions (Roche Applied Science ${ }^{\circledR}$, Roche, Mannheim, Germany). The upper normal limit for MIA was $10.0 \mathrm{ng} / \mathrm{ml}$.
Table I. Overview of study patients, classified according to the American Joint Committee on Cancer 2002 staging system (26).

\begin{tabular}{llcc}
\hline Characteristic & Gender & Adjuvantly treated & Non-adjuvantly treated \\
\hline \multirow{2}{*}{ Stage III } & Female & 13 & 3 \\
\multirow{3}{*}{ Stage IV } & Male & 9 & 3 \\
& Female & 5 & 21 \\
& Male & 5 & 41 \\
\hline Total & & 32 & 68 \\
\hline
\end{tabular}

Statistical analysis. To analyze the disease manifestation in patients with metastatic melanoma receiving either adjuvant or therapeutic vaccination immunotherapy with DCs, two separate receiver operator characteristic (ROC) analyses were performed and the area under the curve (AUC) was calculated. Confidence intervals for the ROC AUC were analyzed using the boot-strap method. All statistical analyses were performed using the statistical software environment R, version 2.9.2. (R Core Team, Vienna, Austria)

\section{Results}

Patients receiving adjuvant vaccination immunotherapy with DCs $(n=32)$. In an adjuvant setting, the serum S100 and MIA levels were within normal range in 31 and 30 patients, respectively, out of a total of 32 patients at the beginning of the therapy. Follow-up examinations and imaging showed that a total of 12 patients had developed at least one new metastasis under vaccination therapy. When the first new metastasis was detected, an elevated value of S100 or MIA was observed in five patients (two had elevated S100 value, two elevated MIA value, and in one patient both markers were elevated). These five patients showed further disease progression and a fatal course. When recurrent disease was detected in the other seven patients with disease progression, both tumor markers remained within the normal range. False-positive elevated tumor markers in adjuvant situations were rare: $\mathrm{S} 100$ was false-positive in $2.2 \%$ and MIA in $5.1 \%$ of events for the given thresholds.

Patients receiving therapeutic vaccination immunotherapy with DCs $(n=68)$. The serum tumor markers S100 and MIA were elevated in 34 and 31 patients, respectively, out of a total of 68 patients at the beginning of the treatment. Followup examinations and imaging showed elevated S100 and MIA level in 58 and 55 patients, respectively. Median survival in this patient group was 431 days. Out of a total of 261 subsequent staging time points, stable disease was seen in 106, whereas progressive disease was seen in 125 and remission in 30 time points. Of the 30 patients with disease remission, 10 had $\mathrm{S} 100$ values within the normal range, 13 had MIA values within the normal range, and in seven patients, both markers remained within the normal range. 


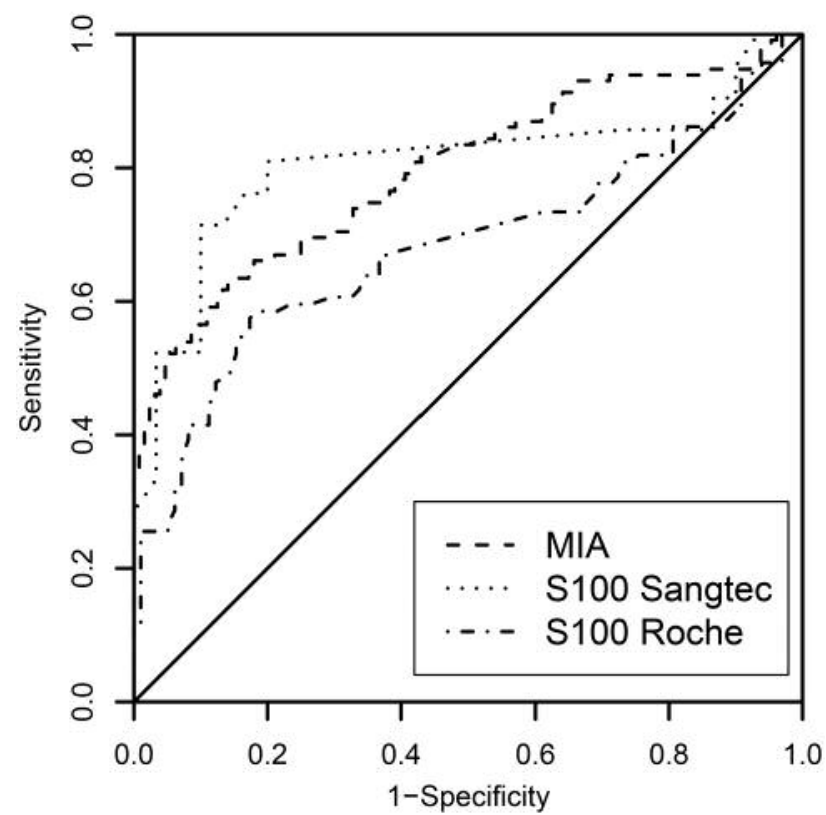

Figure 1. Receiver operator characteristic (ROC) curve of the tumor markers S100 and melanoma-inhibitory activity (MIA) to detect tumor growth in patients with metastatic melanoma receiving therapeutic vaccination immunotherapy with dendritic cells $(n=68)$. The area under the curve for MIA (0.797) is higher when compared to S100 Roche (0.681) and slightly lower when compared to S100 Sangtec (0.807).

The sensitivity in identifying disease progression by increasing serum values is shown in the ROC curve (Figure 1). The ROC AUC was higher for MIA (0.80) than for S100 measured with the Roche assay (0.68, Figure 1; Table II) and comparable to the ROC AUC measured with the Sangtec assay (0.81, Figure 1; Table II).

Overall analysis of the whole study population $(n=100)$. An overall analysis including all 100 patients in order to test the sensitivity in discriminating between tumor-free patients and those with detectable metastatic manifestation was performed (Figure 2). The results show that the AUC for MIA (0.784 and 0.725 , respectively) was higher than the AUC of S100 (0.721 and 0.688, respectively; Figure 2, Table III).

\section{Discussion}

In recent years, comparative studies have shown that both S100 and MIA display a high sensitivity in the staging and monitoring of patients with melanoma (21-25). Two studies including 50 and 48 patients demonstrated superior sensitivity of MIA when compared to $\mathrm{S} 100(22,23)$. On the other hand, S100 has been shown to display a higher sensitivity in the detection of recurrent disease in adjuvantly treated patients (24). Moreover, in a prospective study, changes of both markers
Table II. Area under the curve (AUC) of the receiver operator characteristic curve for detection of tumor progression for the tumor markers S100 and melanoma-inhibitory activity (MIA) with 5\% and 95\% bootstrap confidence intervals. Data are shown for patients with metastatic melanoma receiving therapeutic vaccination immunotherapy with dendritic cells $(n=68)$.

\begin{tabular}{lcc}
\hline Marker & AUC & $95 \%$ Confidence interval \\
\hline MIA & 0.797 & $0.746-0.844$ \\
S100 Sangtec & 0.807 & $0.678-0.919$ \\
S100 Roche & 0.681 & $0.615-0.746$ \\
\hline
\end{tabular}

Table III. Area under the curve (AUC) of the receiver operator characteristic curve for detection of tumor presence for the tumor markers S100 and melanoma-inhibitory activity (MIA) with 5\% and 95\% bootstrap confidence intervals. Data are shown for the whole study population $(n=100)$.

\begin{tabular}{lcc}
\hline Marker & AUC & 95\% Confidence interval \\
\hline MIA (compared to S100 Roche) & 0.784 & $0.751-0.815$ \\
MIA (compared to S100 Sangtec) & 0.725 & $0.657-0.788$ \\
S100 (Roche) & 0.721 & $0.684-0.757$ \\
S100 (Sangtec) & 0.688 & $0.630-0.743$ \\
\hline
\end{tabular}

correlated with tumor burden in patients with advanced-stage disease, but were not superior to lactate dehydrogenase (25).

In our study, both S100 and MIA demonstrated high sensitivity for melanoma. This confirms the findings of Auge et al., where S100 and MIA were shown to be useful markers related to prognostic factors in patients with metastatic melanoma, being even more effective when used in combination (29). Thus, when an elevated serum value of S100 or MIA in patients with without clinical evidence of melanoma is seen, imaging should be performed in order to rule out distant metastasis. However, based on our results, the sensitivity of MIA in detecting tumor seems to be higher when compared to S100 (Figure 2).

In our 68 patients with metastatic melanoma with measurable disease, we found values within the normal range in 10 patients (S100 only), in 13 patients (MIA only), and in 7 patients (both markers). However, in the majority of these patients, tumor progression was indeed identified with high sensitivity by rising tumor markers. In the ROC curve for these patients, the AUC for MIA was comparable or higher than that for S100, indicating that MIA was superior to S100 (Figure 1).

As MIA is known to inhibit immune cell proliferation and cytotoxicity (28), it might correlate with tumor-induced immunosuppression in vivo and with treatment failure, especially in patients treated with immunotherapeutic agents. 

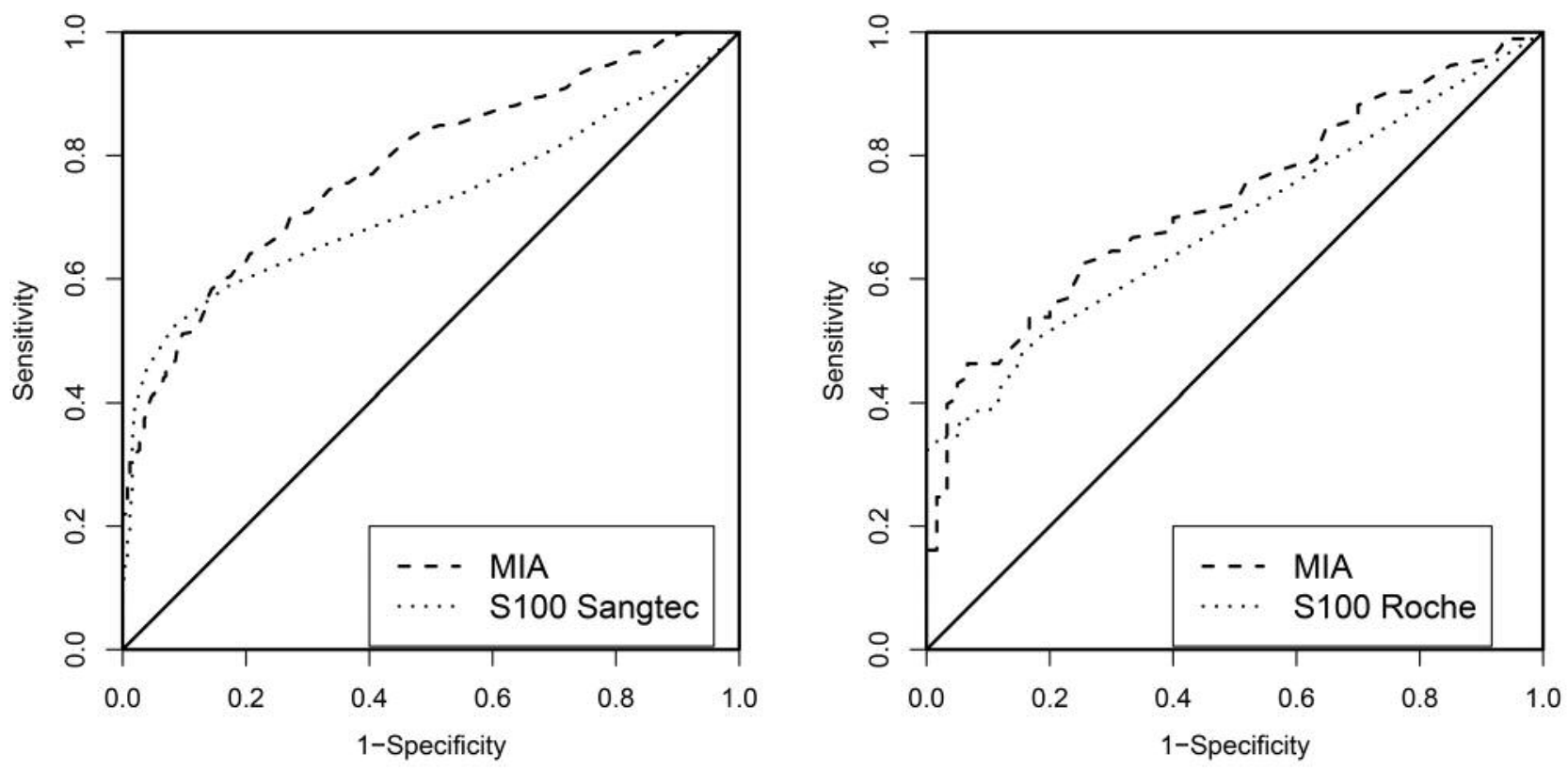

Figure 2. Receiver operator characteristic (ROC) curve of the tumor markers S100 by two assays and melanoma-inhibitory activity (MIA) to identify presence of tumor in the whole study population $(n=100)$. With an area under the curve of 0.784 and 0.725, MIA is superior when compared to S100 (0.721 and 0.688 , respectively).

Thus, studies comparing MIA levels with the response to different therapies are needed in order to evaluate MIA not only to monitor the course of disease, but also as a prognostic marker in immunotherapy.

In conclusion, S100 and MIA showed high sensitivity and specificity in our patients with melanoma receiving either adjuvant or therapeutic vaccination immunotherapy with DCs. In an adjuvant setting, recurrent disease was not always identified by an elevated S100 or MIA level. On the other hand in patients with measurable disease, both S100 and MIA showed a correlation with the clinical course in most patients. However, clinical and imaging examinations in these patients are still absolutely unrevealed. Comparing both markers, MIA showed superior sensitivity in detecting progressive disease when compared to S100 in our study and therefore MIA seems to be more useful in monitoring of patients under immunotherapy.

\section{Acknowledgements}

This project was supported by the German Research Foundation (DFG) via Collaborative Research Center grant SFB 643 (C1).

\section{References}

1 Thompson JF, Scolyer RA and Kefford RF: Cutaneous melanoma. Lancet 365: 687-701, 2005.

2 Uslu U, Schuler G and Breuninger B: Factors influencing disease progression in patients with head and neck melanoma. Anticancer Res 37: 3811-3816, 2017.
3 Morton DL, Thompson JF, Cochran AJ, Mozzillo N, Nieweg OE, Roses DF, Hoekstra HJ, Karakousis CP, Puleo CA, Coventry BJ, Kashani-Sabet M, Smithers BM, Paul E, Kraybill WG, McKinnon JG, Wang HJ, Elashoff R and Faries MB: Final trial report of sentinel-node biopsy versus nodal observation in melanoma. N Engl J Med 370: 599-609, 2014.

4 Chapman PB, Hauschild A, Robert C, Haanen JB, Ascierto P, Larkin J, Dummer R, Garbe C, Testori A, Maio M, Hogg D, Lorigan P, Lebbe C, Jouary T, Schadendorf D, Ribas A, O'Day SJ, Sosman JA, Kirkwood JM, Eggermont AM, Dreno B, Nolop K, Li J, Nelson B, Hou J, Lee RJ, Flaherty KT and McArthur GA: Improved survival with vemurafenib in melanoma with BRAF V600E mutation. N Engl J Med 364: 2507-2516, 2011.

5 Flaherty KT, Puzanov I, Kim KB, Ribas A, McArthur GA, Sosman JA, O'Dwyer PJ, Lee RJ, Grippo JF, Nolop K and Chapman PB: Inhibition of mutated, activated BRAF in metastatic melanoma. N Engl J Med 363: 809-819, 2010.

6 Hodi FS, O’Day SJ, McDermott DF, Weber RW, Sosman JA, Haanen JB, Gonzalez R, Robert C, Schadendorf D, Hassel JC, Akerley W, van den Eertwegh AJ, Lutzky J, Lorigan P, Vaubel JM, Linette GP, Hogg D, Ottensmeier CH, Lebbé C, Peschel C, Quirt I, Clark JI, Wolchok JD, Weber JS, Tian J, Yellin MJ, Nichol GM, Hoos A and Urba WJ: Improved survival with ipilimumab in patients with metastatic melanoma. N Engl J Med 363: 711-723, 2010.

7 Robert C, Thomas L, Bondarenko I, O'Day S, Weber J, Garbe C, Lebbe C, Baurain JF, Testori A, Grob JJ, Davidson N, Richards J, Maio M, Hauschild A, Miller WH Jr, Gascon P, Lotem M, Harmankaya K, Ibrahim R, Francis S, Chen TT, Humphrey R, Hoos A and Wolchok JD: Ipilimumab plus dacarbazine for previously untreated metastatic melanoma. $\mathrm{N}$ Engl J Med 364: 2517-2526, 2011. 
8 Hodi FS, Chesney J, Pavlick AC, Robert C, Grossmann KF, McDermott DF, Linette GP, Meyer N, Giguere JK, Agarwala SS, Shaheen M, Ernstoff MS, Minor DR, Salama AK, Taylor MH, Ott PA, Horak C, Gagnier P, Jiang J, Wolchok JD and Postow MA: Combined nivolumab and ipilimumab versus ipilimumab alone in patients with advanced melanoma: 2-year overall survival outcomes in a multicentre, randomised, controlled, phase 2 trial. Lancet Oncol 17: 1558-1568, 2016.

9 Robert C, Karaszewska B, Schachter J, Rutkowski P, Mackiewicz A, Stroiakovski D, Lichinitser M, Dummer R, Grange F, Mortier L, Chiarion-Sileni V, Drucis K, Krajsova I, Hauschild A, Lorigan P, Wolter P, Long GV, Flaherty K, Nathan P, Ribas A, Martin AM, Sun P, Crist W, Legos J, Rubin SD, Little SM and Schadendorf D: Improved overall survival in melanoma with combined dabrafenib and trametinib. N Engl J Med 372: 30-39, 2015.

10 Gross S, Erdmann M, Haendle I, Voland S, Berger T, Schultz E, Strasser E, Dankerl P, Janka R, Schliep S, Heinzerling L, Sotlar K, Coulie P, Schuler G and Schuler-Thurner B: Twelve-year survival and immune correlates in dendritic cell-vaccinated melanoma patients. JCI Insight 2 pii: 91438, 2017.

11 Boudewijns S, Bloemendal M, Gerritsen WR, de Vries IJ and Schreibelt G: Dendritic cell vaccination in melanoma patients: From promising results to future perspectives. Hum Vaccin Immunother 12: 2523-2528, 2016.

12 Uslu U, Erdmann M, Schliep S, Dörrie J, Schaft N, Schuler G and Schuler-Thurner B: Sarcoidosis under dendritic cell vaccination immunotherapy in long-term responding patients with metastatic melanoma. Anticancer Res 37: 3243-3248, 2017.

13 Wimmers F, Aarntzen EH, Duiveman-deBoer T, Figdor CG, Jacobs JF, Tel $\mathrm{J}$ and de Vries IJ: Long-lasting multifunctional CD8+ T-cell responses in end-stage melanoma patients can be induced by dendritic cell vaccination. Oncoimmunology 5: e1067745, 2016.

14 Donato R: Intracellular and extracellular roles of S100 proteins. Microsc Res Tech 60: 540-551, 2003.

15 Zimmer DB, Wright Sadosky P and Weber DJ: Molecular mechanisms of S100-target protein interactions. Microsc Res Tec 60: 552-559, 2003.

16 Ghanem G, Loir B, Morandini R, Sales F, Lienard D, Eggermont $A$ and Lejeune F: On the release and half-life of S100B protein in the peripheral blood of melanoma patients. Int J Cancer 94: 586-590, 2001.

17 Ohsie SJ, Sarantopoulos GP, Cochran AJ and Binder SW: Immunohistochemical characteristics of melanoma. J Cutan Path 35: 433-444, 2008.

18 Hauschild A, Engel G, Brenner W, Gläser R, Mönig H, Henze E and Christophers E: Predictive value of serum S100B for monitoring patients with metastatic melanoma during chemotherapy and/or immunotherapy. Br J Dermatol 140: 10651071, 1999.

19 Garbe C, Hauschild A, Volkenandt M, Schadendorf D, Stolz W, Reinhold U, Kortmann RD, Kettelhack C, Frerich B, Keilholz U, Dummer R, Sebastian G, Tilgen W, Schuler G, Mackensen A and Kaufmann R: Evidence and interdisciplinary consense-based German guidelines: diagnosis and surveillance of melanoma. Melanoma Res 17: 393-399, 2007.
20 Schmidt J, Riechers A and Bosserhoff AK: MIA- a new target protein for malignant melanoma therapy. Histol Histopathol 28: 421-426, 2013.

21 Bosserhoff AK, Kaufmann M, Kaluza B, Bartke I, Zirngibl H, Hein R, Stolz W and Buettner R: Melanoma-inhibiting activity, a novel serum marker for progression of malignant melanoma. Cancer Res 57: 3149-3153, 1997.

22 Juergensen A, Holzapfel U, Hein R, Stolz W, Buettner R and Bosserhoff A: Comparison of two prognostic markers for malignant melanoma: MIA and S100 beta. Tumour Biol 22: 54$58,2001$.

23 Tas F, Yasasever V, Duranyildiz D, Camlica H, Ustuner Z, Aydiner A and Topuz E: Clinical value of protein S100 and melanoma-inhibitory activity (MIA) in malignant melanoma. Am J Clin Oncol 27: 225-228, 2004.

24 Garbe C, Leiter U, Ellwanger U, Blaheta HJ, Meier F, Rassner $\mathrm{G}$ and Schittek B: Diagnostic value and prognostic significance of protein S-100beta, melanoma-inhibitory activity, and tyrosinase/MART-1 reverse transcription-polymerase chain reaction in the follow-up of high-risk melanoma patients. Cancer 97: 1737-1745, 2003.

25 Deichmann M, Benner A, Kuner N, Wacker J, Waldmann V and Näher H: Are responses to therapy of metastasized malignant melanoma reflected by decreasing serum values of S100beta or melanoma inhibitory activity (MIA)? Melanoma Res 11: 291296, 2001.

26 Balch CM, Buzaid AC, Soong SJ, Atkins MB, Cascinelli N, Coit DG, Fleming ID, Gershenwald JE, Houghton A Jr, Kirkwood JM, McMasters KM, Mihm MF, Morton DL, Reintgen DS, Ross MI, Sober A, Thompson JA and Thompson JF: Final version of the American Joint Committee on Cancer staging system for cutaneous melanoma. J Clin Oncol 19: 3635-3648, 2001.

27 Baur AS, Lutz MB, Schierer S, Beltrame L, Theiner G, Zinser E, Ostalecki C, Heidkamp G, Haendle I, Erdmann M, Wiesinger M, Leisgang W, Gross S, Pommer AJ, Kämpgen E, Dudziak D, Steinkasserer A, Cavalieri D, Schuler-Thurner B and Schuler G: Denileukin diftitox (ONTAK) induces a tolerogenic phenotype in dendritic cells and stimulates survival of resting Treg. Blood 122: 2185-2194, 2013.

28 Jachimczak P, Apfel R, Bosserhoff AK, Fabel K, Hau P, Tschertner I, Wise P, Schlingensiepen KH, Schuler-Thurner B and Bogdahn U: Inhibition of immunosuppressive effects of melanoma-inhibiting activity (MIA) by antisense techniques. Int J Cancer 113: 88-92, 2005.

29 Auge JM, Molina R, Filella X, Bosch E, Gonzalez Cao M, Puig S, Malvehy J, Castel T and Ballesta AM: S-100beta and MIA in advanced melanoma in relation to prognostic factors. Anticancer Res 25: 1779-1782, 2005. 